EESTI NSV TEADUSTE AKADEEMIA TOIMETISED. 21. KOIDE KEEMIA * GEOLOOGIA. 1972, NR. 4

ИЗВЕСТИЯ АКАДЕМИИ НАУК ЭСТОНСКОИ ССР. ТОМ 21 ХИМИЯ * ГЕОЛОГИЯ. 1972, № 4

\title{
ГАЗОВАЯ ХРОМАТОГРАФИЯ ГАЛОГЕНОПРОИЗВОДНЫХ АЛЛИЛЬНОГО ТИПА
}

До настоящего времени извесіны лиш неміногие случаи использования метода газовой хроматографии для анализа низших галогенопроизводных аллильного тиня Причиной неприменимости метода является крайняя чувствительность аллильных галогенопроизводных даже к незначительным термическим и каталитическим факторам, возникающим неизбежно в процессе обычных газохроматографических определений.

Настоящая работа посвящена разрабботке надежного и, возможно, более точного метода газовой хроматографии для определения органических галогенопроизводных аллильного типа, который можно применить, в частности, для анализа фракции хлоридов $\mathrm{C}_{10}$, получаемых при реакциях теломеризации изопрена [1] и пиперилена [리 с их гидрохлоридами. Содержание аллильных хлоридов в этих смесях определялось химическим методом [3].

Для исследования был выбран метод капиллярной газовой хроматографии, который по сравнению с насадочной газовой хроматографией позволяет значительно снизить неблагоприятное влияние на анализируемое вещество повышенных температур и продолжительности определений, а также материала насадки.

В качестве эталона для изучения эффективности и надежности разрабатываемых методик был выбран геранилхлорид - транс-1-хлор-3,7диметилоктадиен-2,6 - синтезированный по методу, разработанному ранее в нашей лаборатории $\left.{ }^{4}\right]$, и обладающий заведомой чистотой (содержание аллильных хлоридов по методу [3] 89,5\%). Это вещество при обычных газохроматографических определениях подвергалось полностью деструкции.

С целью уменьшения температуры и продолжительности газохроматографических определений нами был испытан ряд жидких фаз. Установлено, что жидкие фазы типа нитрилов обеспечивают наименьшие времена удерживания и одновременно обладают высокой селективностью разделения для большинства веществ, в том числе и по отношению к галогенопроизводным. Первыми были испытаны $\beta, \beta^{\prime}$-оксидипропионитрил и $\beta, \beta^{\prime}$-тиодипропионитрил, которые, однако, обладали слишком высокой летучестью в условиях капиллярной газовой хроматографии, и колонки быстро теряли свою разделнтельную способность. Кроме того, большой фон паров этих жидких фаз уменьшал стабнльность нулевой линии. С целью уменьшения давления паров жидкой фазы были испытаны ци- $\beta$-цианэтиловый эфнр гликоля и три- $\beta$-цианэтнловый эфир глицерола, последний оказался наиболее стабильным. Результаты опытов, приведенные в таблице, показывают, что снижение толщины пленки жидких фаз при применении нитрилов позволяет снизить температуру опреде- 


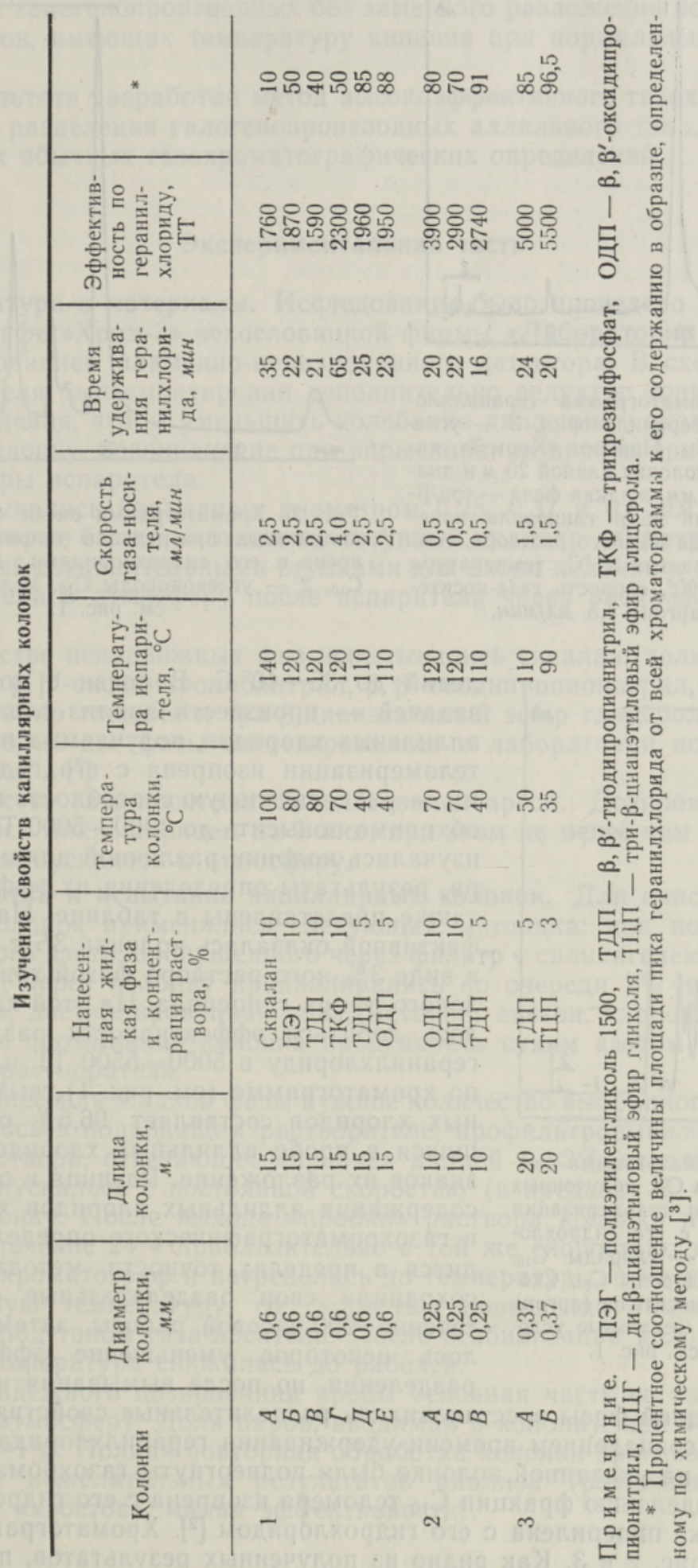




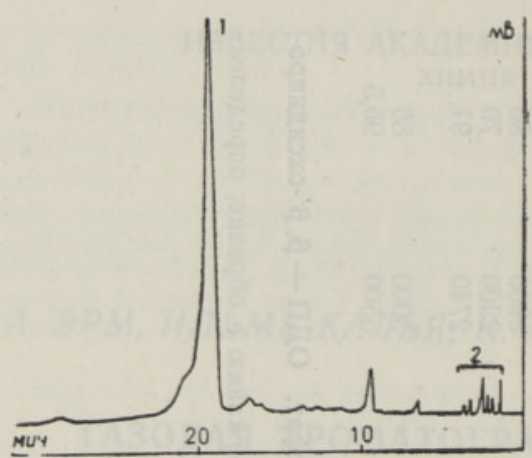

Рис. 1. Хроматограмма геранилхлорида. 1 - геранилхлорид, 2 - углеводороды $\mathrm{C}_{10}$. Прибор: «Хром-3», капиллярная колонка длиной 20 м и диаметром 0,37 мм, жидкая фаза - три- $\beta$ цианэтиловый эфир глицерола, нанесенный в виде $3 \%$-ного раствора, температура анализа $35^{\circ} \mathrm{C}$, температура испарителя $90^{\circ}$, скорость газа-носителя (аргон) 1,5 м//мин.

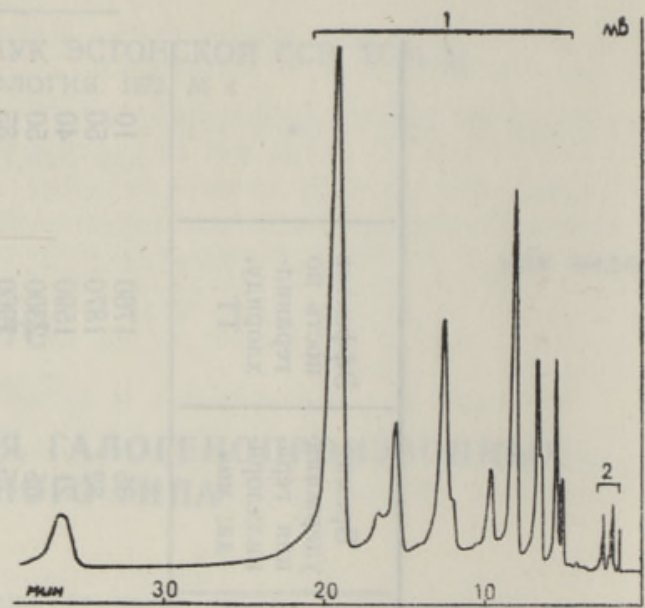

Рнс. 2. Хроматограмма смеси хлоридов $\mathrm{C}_{10}$, полученных при реакции теломеризации изопрена с его гидрохлорндами. 1 - хлориды $\mathrm{C}_{10}, 2$ - углеводороды $\mathrm{C}_{10}$. Условия анализа см. рис. 1 .

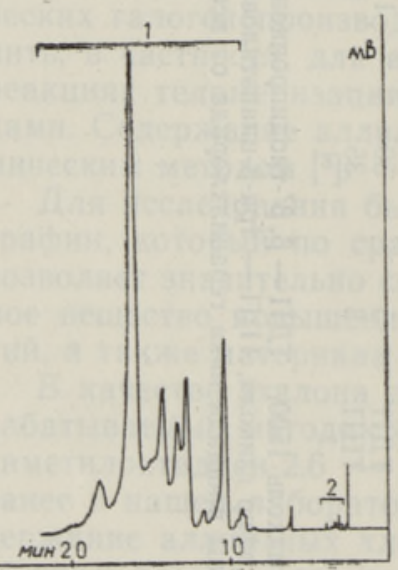

Рис. 3. Хроматограмма смеси хлоридов $\mathrm{C}_{10}$, полученных при реакции теломеризации пиперилена с его гидрохлоридами. 1 - хлориды $\mathrm{C}_{10}$, 2 - углеводороды $\mathrm{C}_{10}$. Ско. рость газа-носителя (аргон) $1,0 \mathrm{мл/мин.} \mathrm{Остальные} \mathrm{усло-}$ вия см. рис. 1.

лений до $35-40^{\circ} \mathrm{C}$. В связи с поставленной задачей - произвести анализ сложной смеси аллильных хлоридов, получаемых при реакции теломеризации изопрена с его гидрохлоридами - разделительную способность колонки необходимо повысить до 4000-5000 ТТ. Поэтому изучались колонки различной длины и диаметра, результаты определения их эффективности также представлены в таблице. Наиболее эффективной оказалась колонка $3 Б$ с нанесенной в виде $3 \%$-ного раствора фазой три- $\beta$-цианэтилового эфира глицерола. На этой колонке удалось добиться эффективности разделения по геранилхлориду в 5000-5500 ТТ и, как видно по хроматограмме (см. рис. 1), выход аллильных хлоридов составляет $96,5 \%$ от содержащихся в пробе аллильных хлоридов без признаков их разложения. Разница в определении содержания аллильных хлоридов химического и газохроматографического определения находится в пределах точности метода. Колонка сохраняла свои разделительные свойства в течение 200-часовой работы, затем наблюдалось некоторое уменьшение эффективности разделения, но после вымывания и нанесения вновь жидкой фазы восстановились разделительные свойства колонки с хорошим совпадением времени удерживания геранилхлорида.

Далее на указанной колонке были подвергнуты газохроматографическому разделению фракции $\mathrm{C}_{10}$ теломера изопрена с его гидрохлоридами [1], а также пиперилена с его гидрохлоридом [2]. Хроматограммы приведены на рис. 2 и 3 . Как видно из полученных результатов, при анализе удается добиться удовлетворительного разделения указанных смесей 
аллильных галогенопроизводных без заметного разложения большинства компонентов, имеющих температуру кипения при нормальных условиях $180-200^{\circ}$.

В результате разработан метод высокоэффективного газохроматографического разделения галогенопроизводных аллильного типа, нестойких в условиях обычных газохроматографических определений.

\section{Экспериментальная часть}

Аппаратура и материалы. Исследование было проведено на газовом хроматографе «Хром-3» чехословацкой фирмы «Лабораторне Пристрое» с использованием пламенно-ионизационного детектора. В схему подачи газа-носителя был вмонтирсван дополнительно редуктор тонкой регули ровки давления, чтобы уменьшить колебания давления у входа в капиллярную колонку, возникающие при впрыскивании проб и при изменении температуры испарителя.

Испытывались капилляры диаметром 0,25, 0,37 и 0,6 мм различной длины, которые были намотаны на латунный цилиндр диаметром 100 м.м, снабженный соединительными втулками для входа колонки и для выхода газа-носителя в атмосферу после исларителя через распределительный вентиль.

В качестве неподвижных фаз испытывались сквалан, полиэтиленгликоль $1500, \beta, \beta^{\prime}$-оксидипропионитрил, $\beta, \beta^{\prime}$-тиодипропионитрил, ди- $\beta$-цианэтиловый эфир гликоля и три- $\beta$-цианэтиловый эфир глицерола, из которых последние две фазы синтезировались в лаборатории по методике, приведенной в [5].

В качестве газа-носителя использовался аргон. Дозирование проб проводилось микрошприцем на 1 мкл, при этом не менее чем $99 \%$ паров вещества выпускалось в атмосферу.

Обработка и испытание капиллярных колонок. Для очистки капиллярных колонок применялась следующая методика: при помощи давления сухого азота, пропущенного через фильтр с силикагелем и стеклянной ватой, через колонку продавливались по очереди $2 \%$-ный раствор детергента, дистиллированная вода, метанол, ацетон, хлороформ и бензол. После промывания колонка продувалась сухим азотом до полного удаления растворителя.

Для нанесения жидкой фазы нужное количество выбранного вещества растворялось в подходящем растворителе, профильтровывалось и количество раствора, отвечающее «пробке» длиной $1-2 \%$ от длины капилляра, пропускалось с постоянной скоростью (в пределах 2-10 мм/сек) через колонку. После выхода «пробки» раствора колонка продувалась азотом в течение 24 ч приблизительно с той же скоростью, затем помещалась в хроматограф и нагревалась до температуры, превышающей на $10^{\circ}$ рабочую температуру, со скоростью повышения температуры $1^{\circ}$ в минуту под током газа-носителя. После стабилизации колонки в течение 2 ч температура снижалась до рабочей.

Для надежного дозирования пробы основная часть ее паров выпускалась в атмосферу. Доля паров, вводимая в колонку, при этом составляет $0,01-1 \%$. Полная повторная обработка колонки производилась при появлении нежелательных результатов анализа (разложение пробы, появление «хвостов», малая эффективность). 


\section{Выводы}

1. Разработан метод газохроматографического анализа галогенопроизводных аллильного типа, нестойких в обычных условиях газохроматографических определений.

2. При применении капиллярных колонок с нанесенными жидкими фазами типа нитрилов с возможно наименьшей толщиной их пленки на примере анализа геранилхлорида достигнута эффективность разделения в 4000-5000 ТТ без заметной изомеризации или деструкции образцов.

3. Разработанный метод использован для газохроматографического разделения фракций галогенопроизводных $\mathrm{C}_{10}$, получаемых при реакциях теломеризации изопрена и пиперилена с их гидрохлоридами.

\section{ЛИ Т Е Р А Т Р А}

1. Л э э т с К. В., ЖОХ, 28, 3096 (1958).

2. Петров А.А.. Раз умова Н. А., Ген усов М. Л., ЖОХ, 28,3220 (1958).

3. Пээтс К. В., Пи ляв ская А. И., К оровкина М. И., ЖОХ, 27, 2969 (1957).

4. Пээ т с К., Т ен г С., Изв. АН ЭССР. Хим. Геол., 16, 284 (1967).

5. Реакции и методы исследования органических соединений, 2, М.-Л., 1952, с. 103.
Ннститут химии
Академии маук Эстонской ССР
Поступила в редакцию 25/XI 1971

\section{A. ERM, ILME KALJA, K. LAATS}

\section{ALLUULSETE HALOGEENUHENDITE GAASIKROMATOGRAAFILINE ANALUUS}

Leiti sobivad ebapüsivate allüülsete kloriidide, näiteks geranüülkloriidi gaasikromatograafilise analüüsi tingimused. Analüüsiti isopreeni ja tema hüdrokloriidide ning piperüleeni ja tema hüdrokloriidide telomerisatsioonireaktsioonil tekkinud $\mathrm{C}_{10}$-kloriide.

\section{A. ERM, ILME KALJA, K. LÄATS}

\section{GAS CHROMATOGRAPHY OF ALLYLIC HALIDES}

Conditions for the capillary gas chromatography of unstable allylic chlorides are found, using geranylchloride as standard. The mixtures of chlorides $\mathrm{C}_{10}$, products of the telomerization reactions of isoprene with its hydrochlorides and piperylene with its hydrochlorides were analyzed. 